\title{
Baicalin alleviates silica-induced lung inflammation and fibrosis by inhibiting the Th17 response in C57BL/6 mice
}

Tao Liu, ${ }^{\dagger, *}$ Wujing Dai,${ }^{\dagger}$ Chao $\mathrm{Li}^{\dagger},{ }^{\dagger}$ Fangwei Liu, ${ }^{\dagger}$ Ying Chen, ${ }^{\dagger}$ Dong Weng, ${ }^{\dagger}$ Jie Chen, ${ }^{*}{ }^{\dagger}$

$\dagger$ Department of Occupational and Environmental Health, School of Public Health, China Medical University, Shenyang 110122, People's Republic of China

* Department of Natural Products Chemistry, School of Pharmacy, China Medical University, Shenyang 110122, People's Republic of China 


\section{Supporting Information}

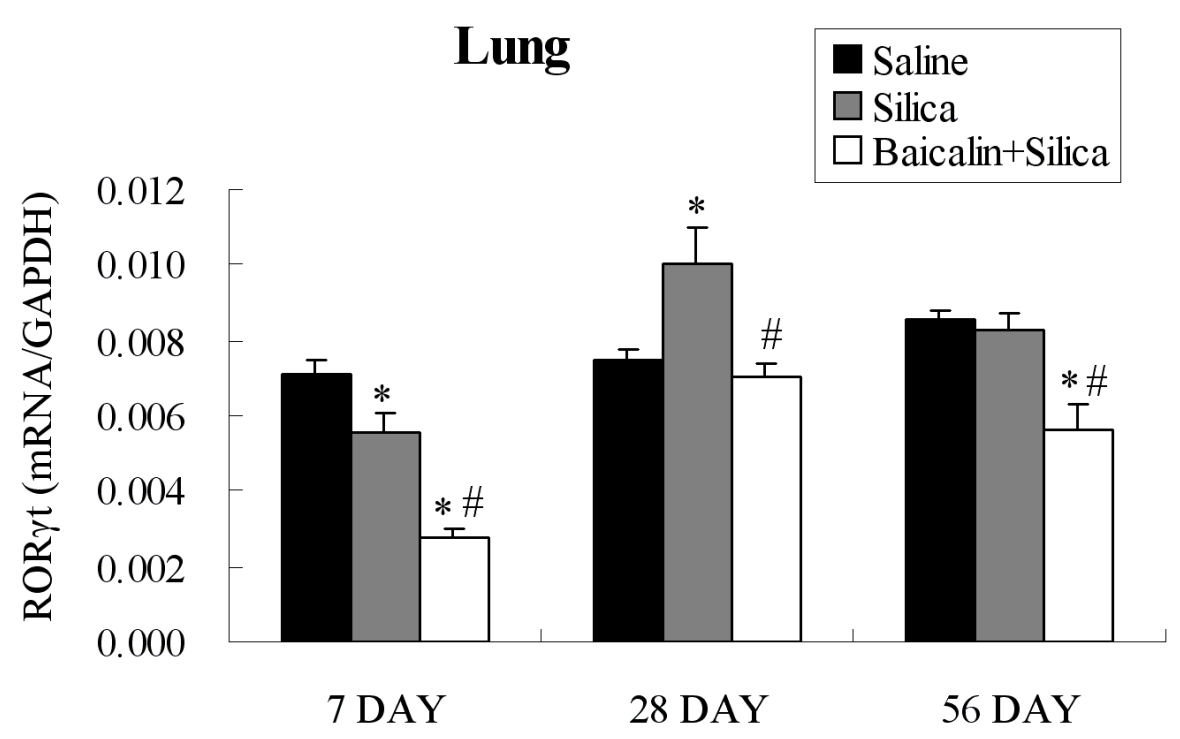

Figure S1. The expression levels of ROR $\gamma \mathrm{t}$ mRNA in the lung were assayed by real time RT-PCR using the $-\Delta \Delta \mathrm{Ct}$ method $(\mathrm{n}=5)$. ( $*$ compared with the saline group, $\mathrm{P}<0.05$; \# compared with the silica group, $\mathrm{P}<0.05)$. 
Lung

$\square$ Silica

$\square$ Baicalin+Silica

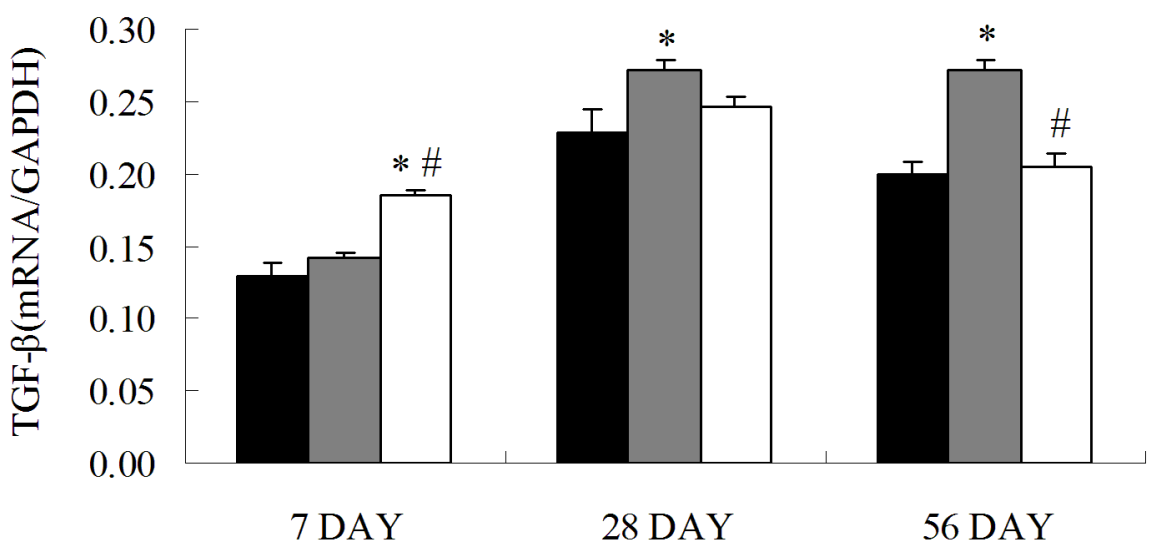

Figure S2. The expression levels of TGF- $\beta$ mRNA in the lung were assayed by real time RT-PCR using the $-\Delta \Delta \mathrm{Ct}$ method $(\mathrm{n}=4-5)$. $(*$ compared with the saline group, $\mathrm{P}<0.05$; \# compared with the silica group, $\mathrm{P}<0.05)$. 
A

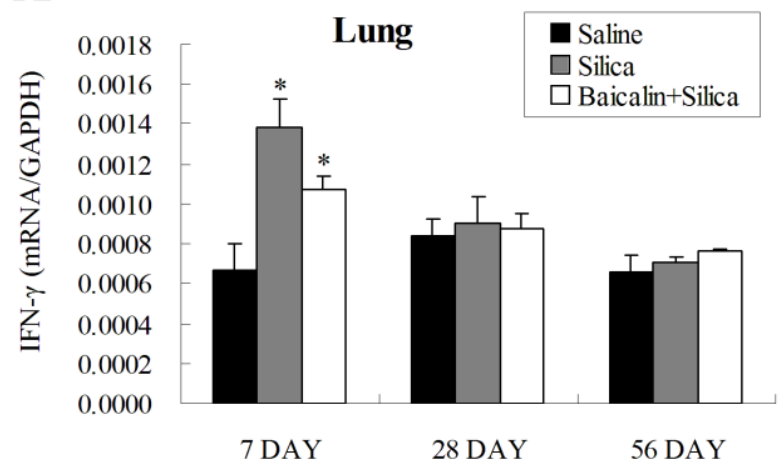

B

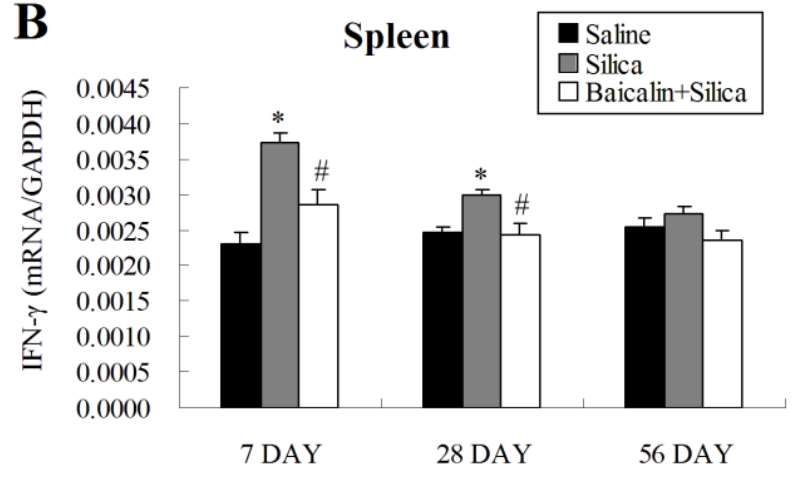

$\mathbf{C}$

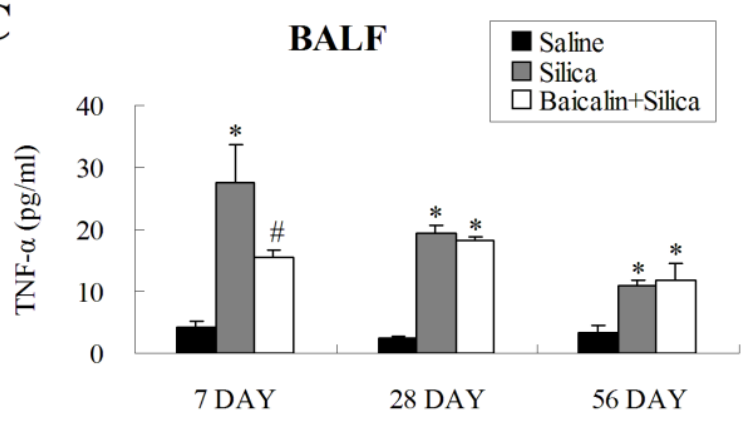

Figure S3. Baicalin decreased Th1 cells in the early phase of the silica-induced inflammatory response. The expression levels of IFN- $\gamma$ mRNA in the lung were assayed by real time RT-PCR using the $-\Delta \Delta$ Ct method $(n=4-5)$; The expression levels of IFN- $\gamma$ mRNA in the spleen were assayed by real time RT-PCR using the $-\Delta \Delta \mathrm{Ct}$ method $(\mathrm{n}=4-5)$; The concentrations of TNF- $\alpha$ in the BALF were quantified by CBA $(\mathrm{n}=4-5)$. (* compared with the saline group, $\mathrm{P}<0.05$; \# compared with the silica group, $\mathrm{P}<0.05)$. 


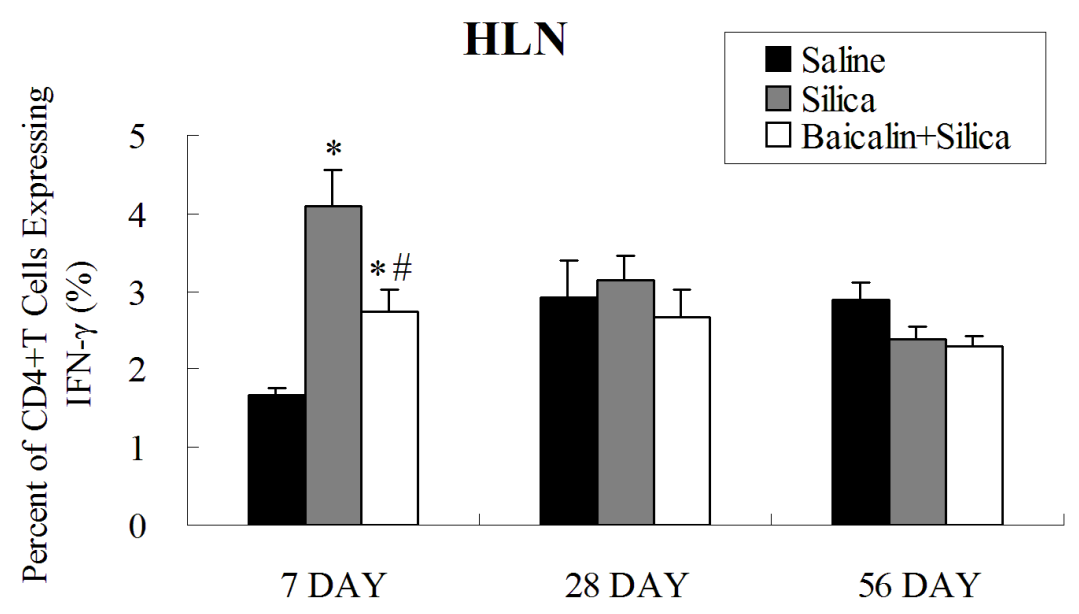

HLN

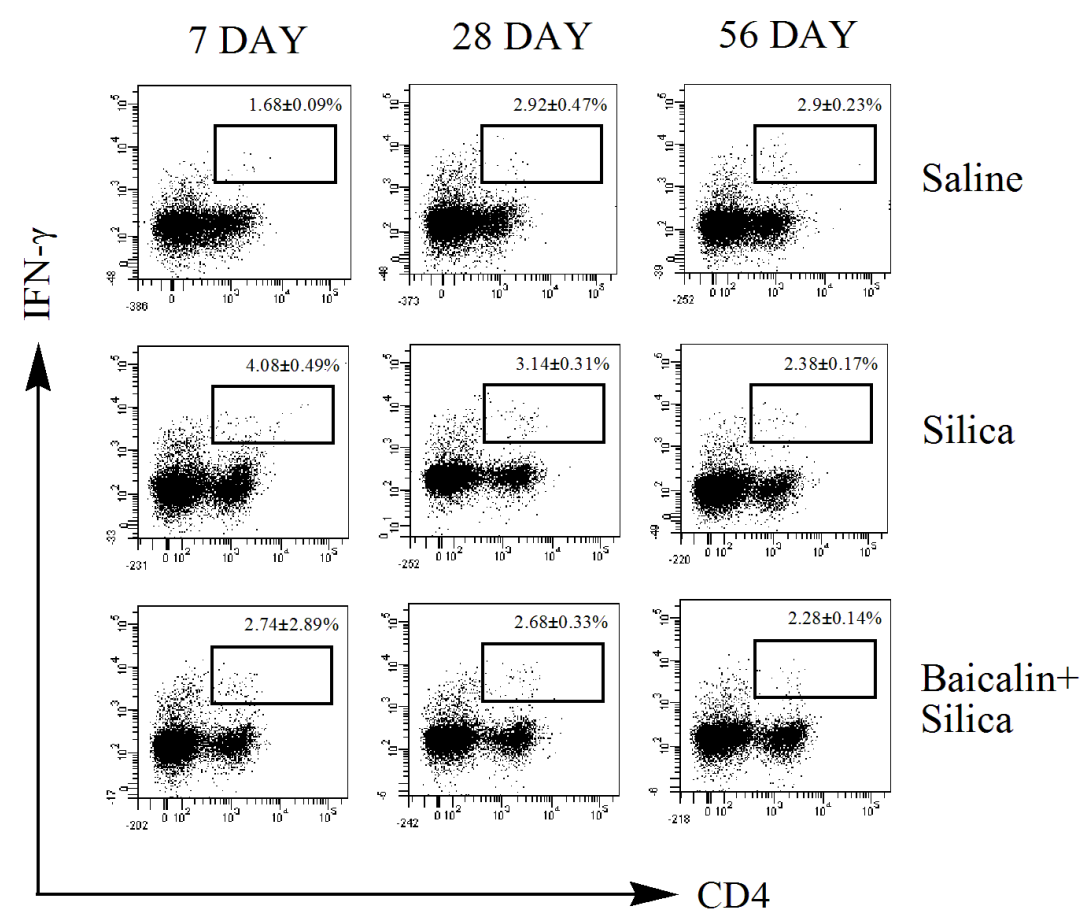

Figure S4. The percentage of CD4+T cells that co-express IFN- $\gamma$ is shown in the graph $(n=4-5)$; Th1 cells in the HLN were calculated by flow cytometry $(n=4-5) .(*$ compared with the saline group, $\mathrm{P}<0.05$; \# compared with the silica group, $\mathrm{P}<0.05$ ). 
A

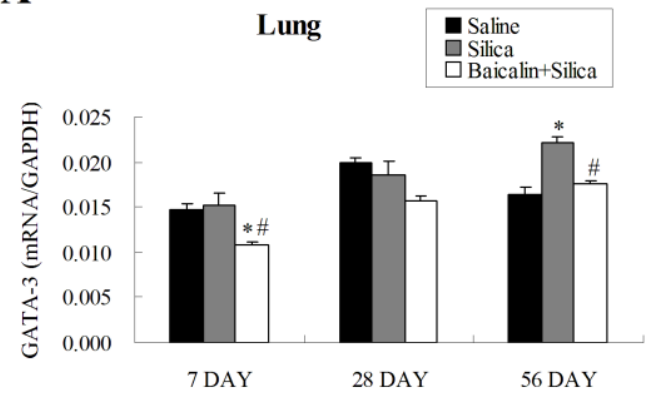

B

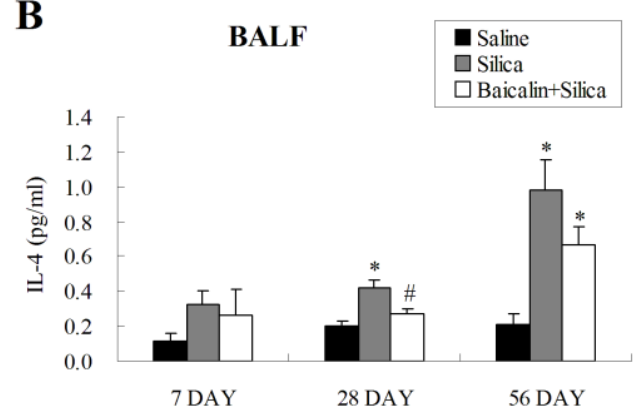

Figure S5. Baicalin alleviated the Th2 response in silica-induced lung fibrosis. The expression levels of GATA-3 mRNA in the lung were assayed by real time RT-PCR using the $-\Delta \Delta \mathrm{Ct}$ method $(\mathrm{n}=4-5)$; The concentrations of IL-4 in the BALF were quantified by CBA $(\mathrm{n}=4-5)$. (* compared with the saline group, $\mathrm{P}<0.05$; \# compared with the silica group, $\mathrm{P}<0.05$ ). 